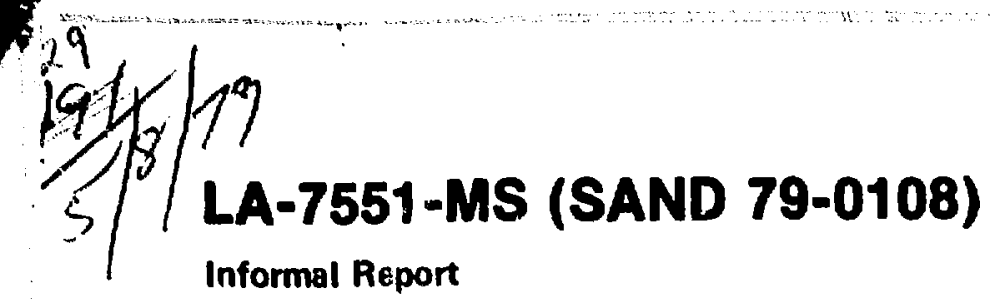

DR. 2555 Informal Report

Problem Statement: International Safeguards for a Light-Water Reactor Fuels

Reprocessing Plant 
LA.7551-MS (SAND 79-0108) Informal Report

uc.78+ 2 Cc- 15

Issued: March 1979

\title{
Problem Statement: International Safeguards \\ for a Light-Water Reactor Fuels \\ Reprocessing Plant
}

\author{
J. P. Shipley \\ E. A. Hakkila \\ R. J. Dietz \\ C. P. Cameron* \\ M. E. Bleck* \\ J. L. Darby*
}

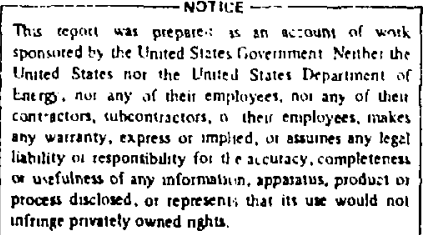

"Organization 1751, Sandia Laboratories, Albuquerque, NM 87115.

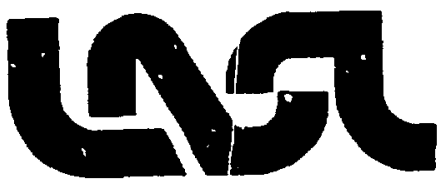




\section{CONTENTS}

\section{ABSTRACT}

1. INTRODUCTION

A. General Problem Statement $\quad 2$

B. Current Features of International Safeguards 3

C. Objectives 4

II. BASE-LINE FACILITY OVERVIEW

A. Introduction $\quad 6$

B. The Process 6

1. Reprocessing Plant 6

2. Conversion Plant 10

C. The Facility 13

1. The Reprocessing Plant 13

2. The Conversion Plant 15

III. DIVERSION THREATS AND TYPES OF COUNTERMEASURES 16

A. Introduction 16

B. Diversion Threats $\quad 17$

1. Diversion Hidden by Measurement Uncertaintjes 17

2. Diversion Unobserved by Containment and Surveillance 18

3. Instrument Tampering 19

4. Data Falsification 20

5. Covert Process Changes $\quad 20$

C. Some Types of Countermeasures $\quad 21$

1. Technical Safeguards Messures 21

2. Process Modifications for Safeguards Improvement 24

3. Institutional Arrangements $\quad 24$

iv. TECHNICAL APPROACH

A. Otjectives $\quad 25$

B. Study Procedure $\quad 2.6$

1. Define Diversion Strategies $\quad 26$

2. Design Materials Accounting and Containment and

3. Evaluate Diversion-Event Characteristics 30

4. Evaluate Overall Diversion-Event Characteristics 30

5. Assess Costs of the Options 31

6. Issue Joint Report 31

ACKNOWLEDGMENTS

$\begin{array}{ll}\text { REFERENLES } & 32\end{array}$ 


\section{FIGURES}

$\begin{array}{ll}\text { 1. Flow diagram for joint project. } & 5\end{array}$

2. Reprocessing plant pre-partition process. $\quad 8$

3. Reprocessing plant plutonium purification process. 9

4. Process flowsheet for Pu (III) oxalate precipitation. 11

5. Separations process building arrangement (conversion not shown). 14

$\begin{array}{ll}\text { 6. Logic tree symbols. } & 28\end{array}$

7. Typical logic tree with incomplete subtree under event Al. 29

8. Completion of subtree under event Al. 30

TABLE

1. Conversion Process Design Pararneters 
PROBLEM STATEMENT: INTERNATIONAL SAFEGUARDS

FOR A

LIGHT-WATER REACTOR FUELS REPROCESSING PLANT

by

J. P. Shipley, E. A. Hakkila, R. J. Dietz,

C. P. Cameron, M. E. Bleck, and J. L. Darby

\begin{abstract}
This report considers the problem of developing international safeguards for a light-water reactor (LWR) fuel reprocessing/conversion facility that combines the Purex process with conversion of plutonium nitrate to the oxide by means of plutonium (III) oxalate precipitation and calcination. Current international safeguards systems are based on the complementary concepts of materials accounting and containment and surveillance, which are designed to detect covert, national diversion of nuclear material. This report discusses the possib!e diversion threats and some types of countermeasures, and it represents the first stage in providing integrated international safeguards system concepts that make optimum use of available rescurces. The development of design methodology to address this problem will constitute a significant portion of the subsequent effort. Additionally, future technology development requirements will be identified.
\end{abstract}




\section{INTRODUCTION}

\section{A. General Problem Statement}

The introduction of reprocessing facilities into the commercial nuclear fuel cycle has underscored a concern that material produced in such a facility might be used for nuclear explosives. This could occur either through diversion from the fuel cycle of fissile material being processed at the plant or the clandestine use of the facility to process fissile material from undeclared feed. The traditional safeguards methods, which depend primarily upon materials balancing by periodic shutdown, cleanout, and physical inventory, may provide adequate safeguards for small-scale demonstration and pilot plants. Large-scale reprocessing plants, however, require much more effective safeguards measures to detect the diversion of relatively small but weapons-significant quantities of nuclear materials that might be obscured by the statistical and measurement uncertainties inherent in high-throughput determinations. For example, dynamic materials measurement and accounting yield more sensitive and timely measurement information than does conventional accounting. In addition, modern containment and surveillance techniques can provide essential assurance that the facility is not being deliberately misoperated and that information gathered by the materials measurement and accounting sy'stem reflects the true state of special nuclear materiais (SNM) within the facility. The problem to be addressed in this series of international safeguards studies is the integration of such technical measures into an effective international sâeguards system.

Preventing the misuse of the materials and facilities in a nuclear fuels repr acessing plant is not exclusively a technical problem. Effective means for safeguarding nuclear materials against subnational diversion can be applied to the problem of national diversion only in the appropriate political envirinment, which must include an initial mutual willingness to implentent effective safeguar's under some bilateral, international, or multinational agreement. ${ }^{1,2}$ Once executed, these agreements, which incorporate limitations stemming from traditional national prerogatives and sansitivities, can effectively preciude a rismber of subsequent technical alternatives. For this reason, it is well to begin this discussion with an assessment of the effect these limitations have on any proposed international safeguards system, which onust by practical necessity and international agreement be based on an effective domestic safeguards system. 


\section{B. Current Features of International Safequards}

The basis for most current international safeguards arrangements is the Treaty on the Non-Proliferation of Nuclear Weapons, ${ }^{3}$ agreed to by over 100 signatory nations since 1970. The detailed terms and conditions under which specific facilities are safeguarded under the Non-Proliferation Treaty (NPT) are negotiated with the International Atomic Energy Agency (IAEA), in accord with the general conditions of Article III of the NPT, set forth in IAEA document INFCIRC/153. ${ }^{4}$

The objective of international safeguards, as declared by these documents, is the "...timely detection of diversion of significant quantities of nuclear material from peaceful riclear activities... ." The emphasis is on nuclear materials control with "...the use of materials accountancy as a safeguards measure of fundamental importance, sith containrnent and surveillance as important complementary measures... .." The manner and frequency of inspections for compliance are negotiated between the IAEA and the host nation on a case-by-case basis and are dccumented in the so-called "Subsidiary Arrangements and Facility Attachments."

The specific objective of the international safeguards system is the independerit verification of the facility-generated reports and statements submitted by the State to the IAEA. The independently verified data are the basis for a conclusion on nondiversion or diversion of nuclear material by the State. The inspector's verification activities consist of independent measurement of materials and audits of records of the facility operator, as we,l as independent observations on the integrity of the containment. Typically, the level of inspector-directed activity involved in sampling and generating measurement data and supporting information is directly related to the degree to which the facility reports and statements are independently verifiable. The provision for independent verification of the facility data is an indispensable element in the design of a facility-operated system that is consistent with the objectives of the IAEA.

The effectiveness of any international safeguards system, therefore, depends on specific facility-oriented features and is further affected in a general way by three major considerations. The first of these is the content of the negotiated safeguards agreernent, which must of necessity recognize all aspects of national sovereignty, sensitilities, and prerogatives; and the host nation's economic and proprietary (technical) advantages, whether real, declared, or imagined. The agreement must be diplorratically acceptable while still satisfying IAEA requirements. 
The second class of considerations centers about the limited resources available to the IAEA in terms of technical capability, inspection time, knowledge, and access to the facility. Currently, the role of the IAEA is to provide an international overlay on the State's safeguards system. In accord with the negotiated agreements, the IAEA employs independent verification of the State's materials accounting data and containment and surveillance techniques to give additional assurance that activities involving nuclear material are proper.

The third class of considerations comprises the inherent technical limitations of safeguards systems, the fundarnental process features of high-throughput nuclear facilities, and the economic constraints of effective materials management consistent with production goals. While these limitations are common to all safeguards systems, present and future, domestic and international, they most seriously affect current international safeguards because some technical options capable of solving safeguards problems may be excluded by agreement or considerations of national sovereignty.

All three sets of constraints effectively bound the allowabie options for international safeguards. The first two are functions of national policy is posture and are not generally amenable to technical solutions. Conversely, within the range of allowable techniral options, the third set of limitations comprises largely technical considerations, which for the most part, are not subject to negotiation. In this paper we will emphasize the technical solutions available for the third set of limitations and how they might influence the negotiable institutional, organizational, and inspection features of international safeguards agreements.

\section{Objectives}

The ultimate objective of the complete study is to develop concepts for an international safeguards system that can provide timely detection of the national diversion of a significant amount of nuclear material from an LWR spent-fuel reprocessing/conversion facility. As shown in Fig. 1, the study will proceed in stages. This first report contains a problem statement, a base-line facility overview, a preliminary discussion of diversion threats and types of countermeasures, and an out!ine of the technical approach to performing the study.

In the second stage of the study, concepts will be prepared by Los Alamos Scientific l_aboratory (LASL) and Sandia for materials measurement and accounting and for containment and surveillance, respectively, in the base-line facility. In the preparation of these concepts, all reasonable technical and inspector options will be considered. In the final stage of the study, these concepts will be merged into a set of 


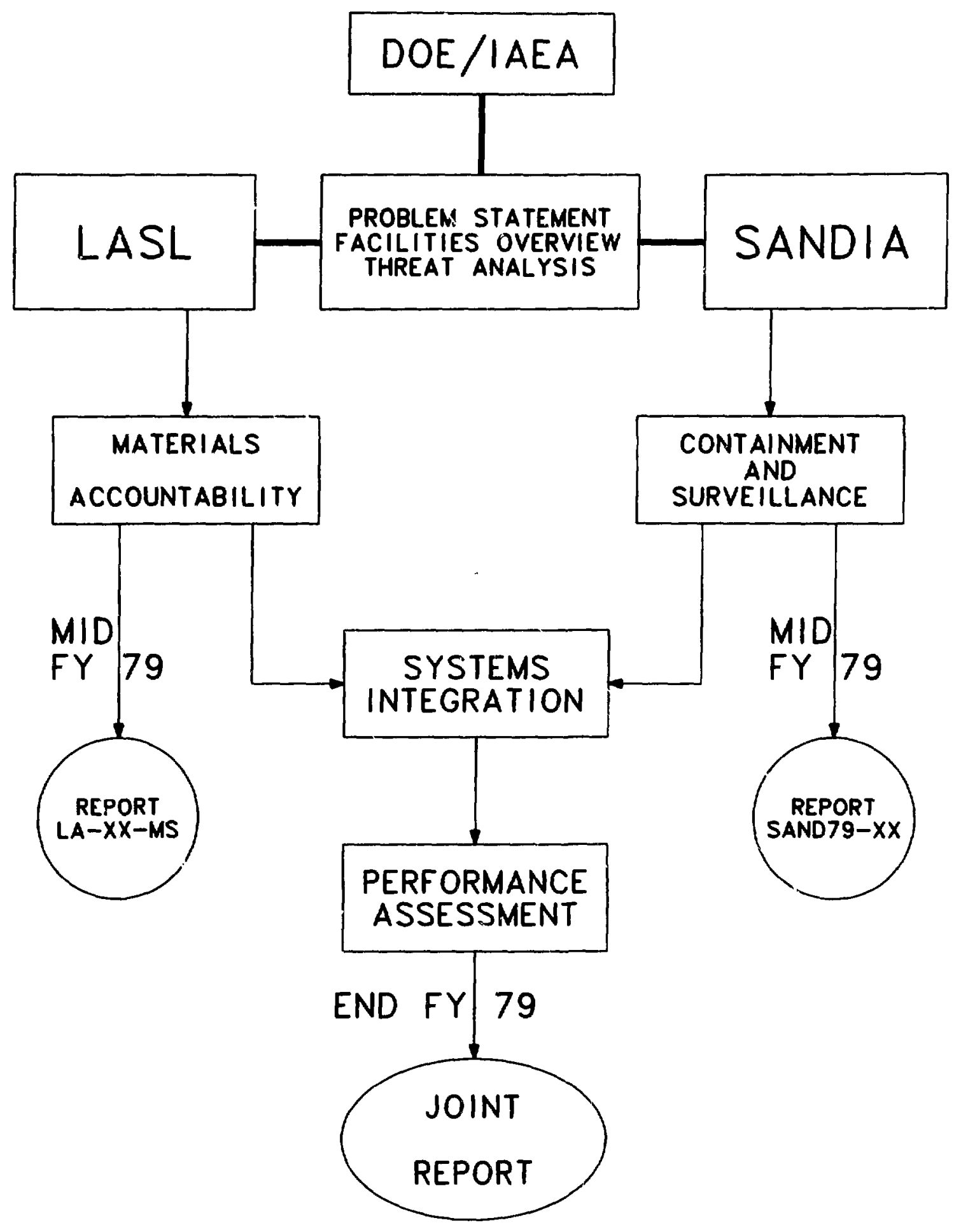

Fig. 1. Flow diagram for joint project. 
integrated systems concepts that will be described in a final, joint report. Tradeoffs among containment and surveillance, materials measurement and accounting, inspection options, and costs will be considered in the development of the integrated system.

Successful completion of the study requires that the techniques of materials accounting and containment and surveillance be integrated in a rational way into a comprehensive international safeguards system. Consequently, much of the effort will be devoted to developing the necessary design and evaluation methodology (see Ser.. IV).

\section{BASE-LINE FACILITY OVERVIEW}

\section{A. Introduction}

This study is based on Purex reprocessing for production of a pure plutonium-nitrate solution and oxalate precipitation for conversion to plutonium-oxide powder. The base-line reprocessing facility chosen for analysis is based on the Allied General Nuclear Services' Barnwell Nuclear Fuels Plant (AGNS-BNFP). This plant has been selected as the base-line facility because its size is representative of the full-scale regional or multinational reprocessing plants that may be built in the near future and because there is a wealth of information available on this facility.

The reference nitrate-to-oxide conversion process is based on precipitation and calcination of plutonium (III) oxalate. Both LASL arid the Savannah River Plant have extensive experience with the process; it consistently produces a readily filterable precipitate with low loss, and it is controlled easiiy at room temperature.

In specifying these facilities as ret. -onces, it is recognized that some features of the plant and process designs are not representative of other designs under consideration. For those areas where design differences among facilities that produce pure plutonium streams are judged to have a significant impact on international safeguards, concepts will be identified that could be applied to other designs.

\section{B. The Process}

Much more detail on the processes can be found in Refs. 5-8.

1. Reprocessing Plant. The reference facility reprocesses $\sim 5 \mathrm{MT}$ of hervy metal as oxide fuel elements per day, or w 1500 MT per year, using conventional Purex technology. The plant is designed to receive and process irradiated power-reactor fuel originally 
containing $\mathrm{UO}_{2}$, or $\mathrm{UO}_{2}$ and $\mathrm{PuO}_{2}$, at a nominal $3.5 \%{ }^{235} \mathrm{U}$ enrichment or $29 \mathrm{~kg}$ of fissile plutonium per ton (or the equivalent) before irradiation. Fuel batches having an average burnup not exceeding $40000 \mathrm{MWd} / \mathrm{MTHM}$ (megawatt days per metric ton of heavy metal) are processed at rates up to $5 \mathrm{MTHM}$ /day after a decay period of at least 160 days. Fuel with a greater fissile content (up to $5 \%{ }^{235} \cup$ or the equivalerit in fissile-plutonium content) may be processed by ciecreasing the plant throughput.

Spent-fuel assemblies arrive at the reprocessing facility by rail or truck and are held in a fuel-storage pool while awaiting processing. The fuel elernents are mechanically sheared into small pieces and the fuel is dissolved with a concentrated nitric-acid solution. Following dissolution, the solution is contacted with TBP in organic solvent to separate most of the fission products from the plutonium and uranium ( $F$ ig. 2 ). The solvent stream containing the plutonium and uranium enters the partitioning step where the bulk of the uranium is separated from the plutonium. The uranium stream is further decontaminated with a solvent-extraction, aqueous-strip cycle and is then concentrated. The concentrated uranyl nitrate passes thrcugh silica-gel beds to remove traces of zirconium and niobium and is stored as the nitrate before conversion to UF ${ }_{6}$ in a separate plant. The plutonium stream from the partitioning cycle is further purified in two separate solvent-extraction and acid-strip process steps (Fig. 3). The plutonium-nitrate solution is concentrated and stored awaiting conversion to plutonium oxide. The wastes from the processes are treated in either liquid- or solid-waste processing systems. Off-gases are treated before being vented to the atmosphere.

The front end of the plant (fuel receiving and storage, feed preparation) involves the handling and dissolution of spent-fuel assemblies containing high beta-gamma radiation levels from associated fission products. Plutonium purity with respect to uranium, fission products, and concentration improves as the material proceeds through the plant. Hence, the attractiveness to diversion also increases. Uranium enrichment in the spent fuel is approximately $1 \%$, requiring only nominal uranium safeguards materials control and accounting measures.

At the headend of the reprocessing facility, spent fuel is received and stored in the form of fuel assemblies containing $\sim 2 \mathrm{~kg} \mathrm{Pu}$ in $200 \mathrm{~kg} \cup$ for BWR fuel, or $4 \mathrm{~kg} \mathrm{Pu}$ in 400 $\mathrm{kg} U$ for PWR fuel. Each assembly also carries $\sim 6 \times 10^{6} \mathrm{Ci} / \mathrm{MT} U$ of lethal, penetratirig radiation after 160 days of cooling. In this area, the diversion of complete fuel assemblies would be necessary to obtain a significant quantity of fissile material.

The capacity of the accountability tank is $8100 \mathrm{~L}$, and it contains $v 15 \mathrm{~g} / \mathrm{L}$ of fission products and $\sim 3 \mathrm{~g} / \mathrm{L}$ Pu. Therefore, $\sim 330 \mathrm{~L}$ of solution must be diverted from the accountability tank to acquire $1 \mathrm{~kg}$ of plutonium. 


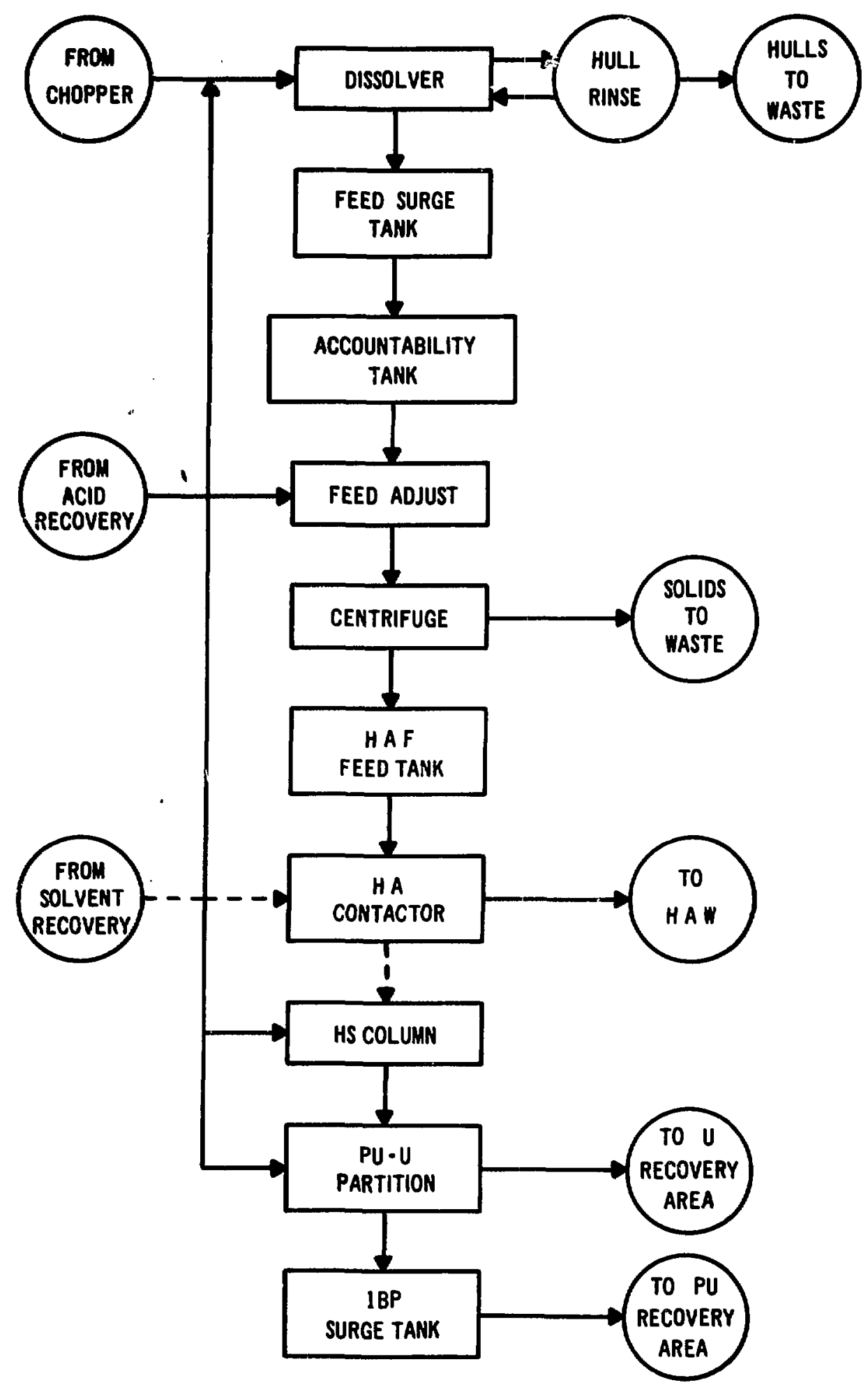

Fig. 2. Reprocessing plant prepartition process. 


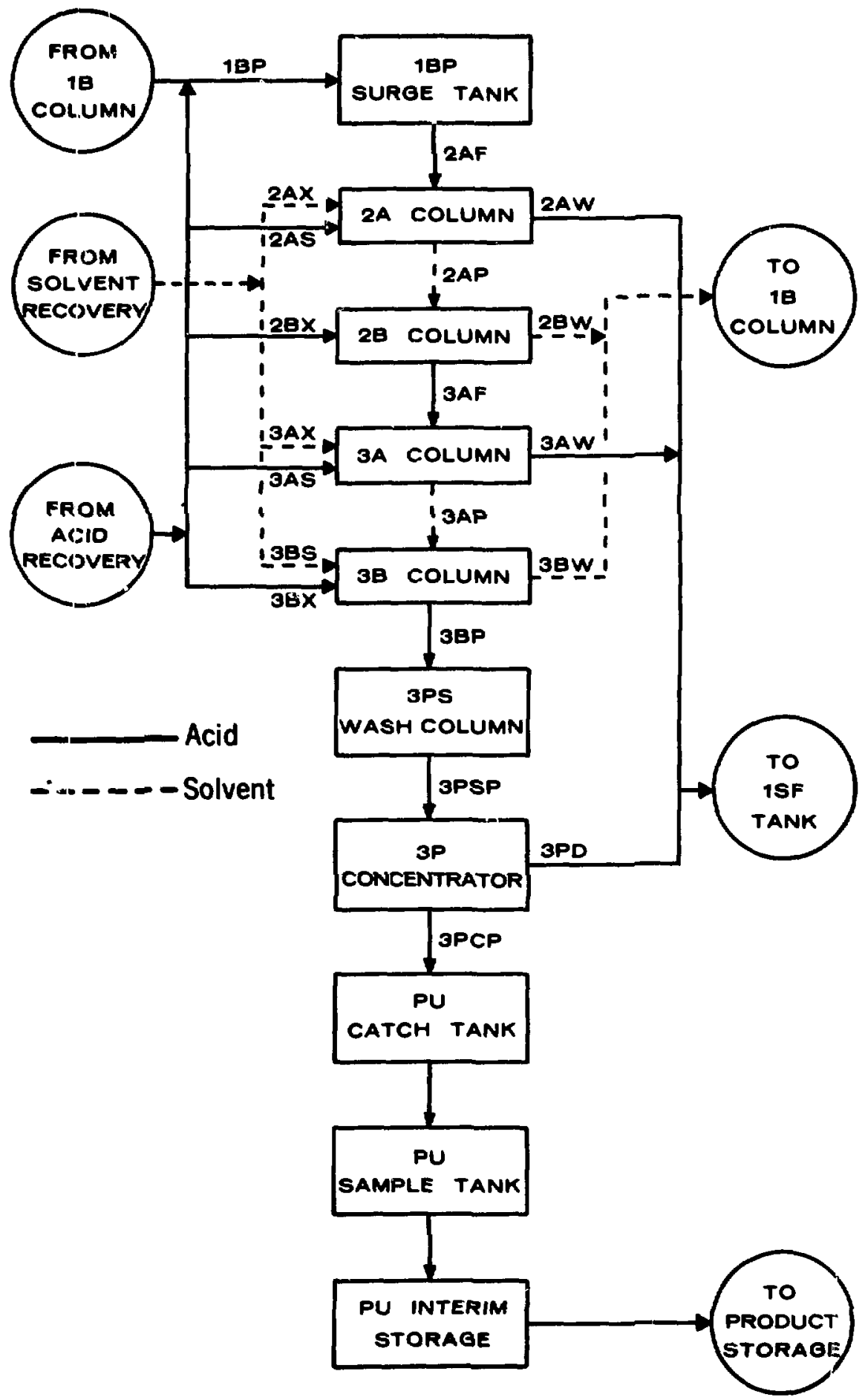

Fig. 3. Fieprocessing plant plutonium purification process. 
The IBP tank immediately following U/Pu partitioning has a 1500-L capacity, and the plutonium concentration is $\sim 5 \mathrm{~g} / \mathrm{L}$ with a $2: 1 \mathrm{U} / \mathrm{Pu}$ ratio. Thus, about $200 \mathrm{~L}$ of solution would be required to obtain $1 \mathrm{~kg}$ of plutonium.

The output of the plutonium purification process, before the $3 P$ concentrator, contains about $50 \mathrm{~g} / \mathrm{L}$ of plutonium as the nitrate; after the $3 P$ concentrator, which might not be necessary if the nitrate-to-oxide conversion facility were collocated, the plutonium concentration is $2250 \mathrm{~g} / \mathrm{L}$. About $20 \mathrm{~L}$ of solution would be required from the concentrator input stream to obtain $1 \mathrm{~kg}$ of plutonium, and $\sim 4 \mathrm{~L}$ would be necessary from the concentrator output stream.

2. Conversion Plant. The reference nitrate-to-oxide conversion process for this study is based on precipitation and calcination of plutonium (III) oxalate. Figure 4 shows a block diagram of the process, and materials transfers, concentrations, and transfer frequencies are summarized in Table $\mathrm{l}$. The design basis throughput is $117 \mathrm{~kg}$ of plutunium product per day. In normal operation, a throughput of $106 \mathrm{~kg}$ of plutonium per day is expected.

Feed solutions containing $30 \mathrm{~g} / \mathrm{L}$ of $\mathrm{Pu}^{4+}$ in $3 \mathrm{M} \mathrm{HNO}$ are transferred to a receipt tank in the conversion facility. The feed is analyzed and then transferred to valence adjustment tanks where hydrazine and ascorbic acid are added to reduce the plutonium to the trivalent state.

The adjusted solution is transferred to a two-stage precipitator and oxalic acid is added to form a dense, easily filtered slurry of plutonium oxalate, $\mathrm{Pu}_{2}\left(\mathrm{C}_{2} \mathrm{O}_{4}\right)_{3}$. This slurry is vacuum-filtered, washed, and aspirated to partial dryness in boats containing sintered-metal filters.

The filter boat is transferred through a tunnel furnace for drying and calcining. The calcined product is cooled, the, unloaded into a container for assay, storage, and shipping.

Unloaded filter boats and precipitator tanks are flushed periodically, and the flush solutions are transferred to the recycle line. Filtrates, wash solutions, powder sweeplings, spills, and rejected product also are transferred to the recycle line.

The combined filtrate and wash solution is treated to destroy hydrazine, ascorbic acid, and oxalic acid, and then concentrated by evaporation. The sweepings and rejected product are batched (500 g Pu) and then dissolved in nitric acid containing fluoride ion. The dissolver solution is blended with the evaporator solution to provide sufficient volume for efficient use of the plutonium capacity of the anion-exchange solumns. Flush solutions are combined, and any oxalic acid is destroyed by digestion. The 10 


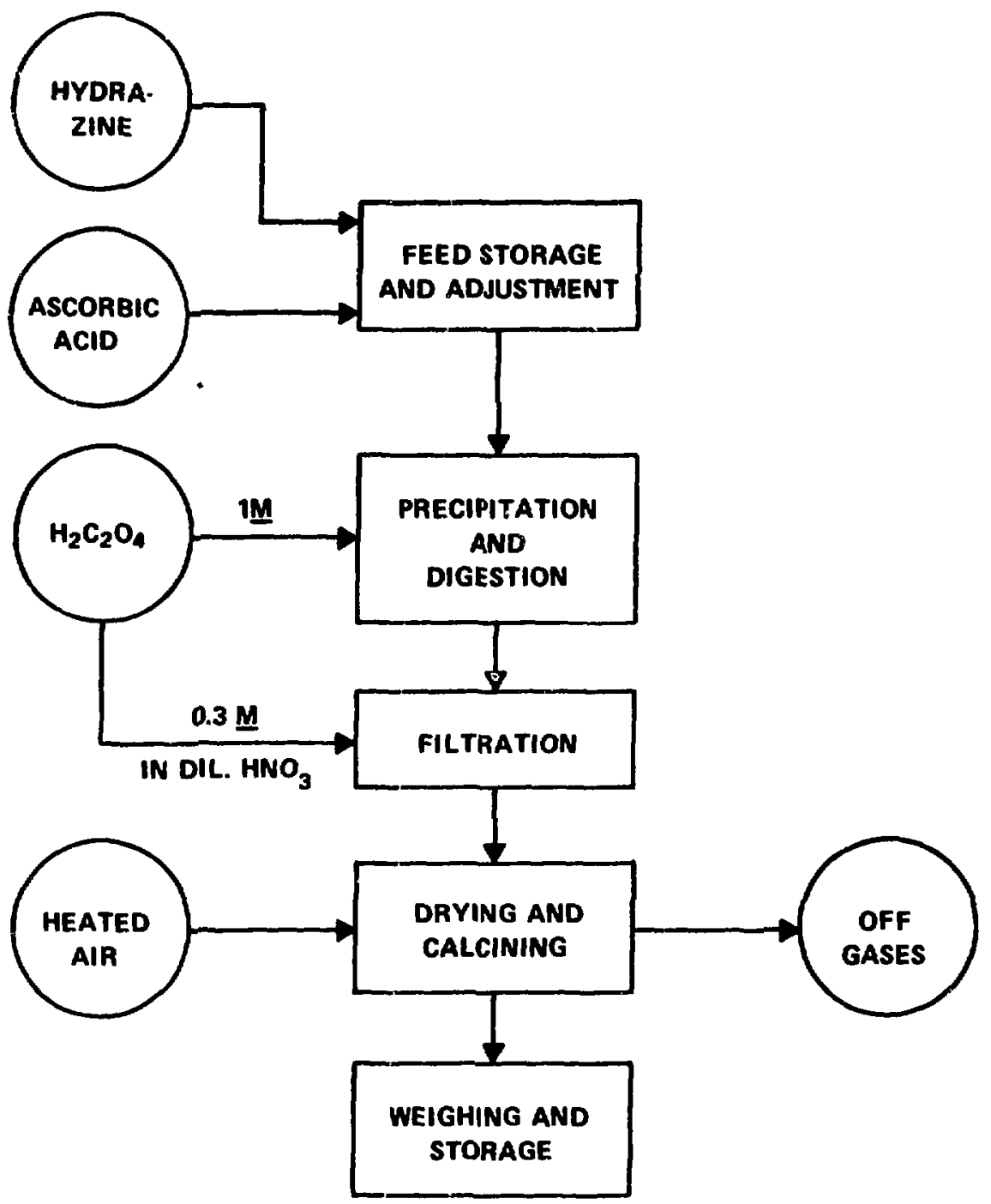

Fig. 4. Process flowsheet for Pu (III) oxalate precipitation. 
TABLE I

CONVERSION PROCESS DESIGN PARAMETERS

Function

Receipt tank feed

Valence adjust feed

Precipitator feed

Pu oxalate boat to furnace

Pu oxide to accountability

Pu product to storage

Filtrate

Precipitator flush

Furnace sweeping

Boat flush

Dump station sweep

Reject product

Evaporator product

vigester product

Precipitator flush

Boat flush

Dissolver product

Ion-exchange waste

Ion-exchange product
Volume or

Weight

per Batch

$200.0 \mathrm{~L}$

$66.67 \mathrm{~L}$

$75.44 \mathrm{~L}$

$4.65 \mathrm{~kg}$

$2.21 \mathrm{~kg}$

$2.18 \mathrm{~kg}$

154.9 L

$109.2 \mathrm{~L}$

$0.85 \mathrm{~kg}$

34.4 L

$0.85 \mathrm{~kg}$

$2.18 \mathrm{~kg}$

$15.49 \mathrm{~L}$

109.1 L

172.1 L

$2.0 \mathrm{~L}$

$202.0 \mathrm{~L}$

$73.0 \mathrm{~L}$
Concentration

$30.0 \mathrm{~g} / \mathrm{L}$

$30.0 \mathrm{~g} / \mathrm{L}$

$2 f 5 \mathrm{~g} / \mathrm{L}$

'2 $\mathrm{kg} / \mathrm{kg}$

$: 2 \mathrm{~kg} / \mathrm{kg}$

$0 . \therefore ? \mathrm{~kg} / \mathrm{kg}$

66.4

$\mathrm{mg} / \mathrm{L}$

4.6

$g / L$

$0.882 \mathrm{~kg} / \mathrm{kg}$

$2.9 \mathrm{~g} / \mathrm{L}$

$0.882 \mathrm{~kg} / \mathrm{kg}$

$0.882 \mathrm{~kg} / \mathrm{kg}$

$0.31 \mathrm{~g} / \mathrm{L}$

$4.5 \mathrm{~g} / \mathrm{L}$

$2.9 \mathrm{~g} / \mathrm{L}$

$250.0 \mathrm{~g} / \mathrm{L}$

$2.2 \mathrm{mg} / \mathrm{L}$

$6.8 \mathrm{~g} / \mathrm{L}$
Frequency

$1 / 1.23 \mathrm{~h}$

$1 / 0.41 \mathrm{~h}$

$1 / 0.41 \mathrm{~h}$

$1 / 0.41 \mathrm{~h}$

$1 / 0.41 \mathrm{~h}$

$1 / 0.4] \mathrm{h}$

$1 / 0.41 \mathrm{~h}$

3/day

1/week

10/day

2/day

1/4 days

$1 / 0.41 \mathrm{~h}$

3/day

2/day

5/day

11/day

11/day 
exchange-column plutonium product is eluted and transferred to the main process line. All waste solutions are transferred to waste management.

For the nitrate-to-oxide conversion process based on plutonium (III) oxalate precipitation, plutonium concentration in the receipt tank would be $\sim 30 \mathrm{~g} / \mathrm{L}$. Therefore, a divertor would need $233 \mathrm{~L}$ of solution for $1 \mathrm{~kg}$ of plutonium. After precipitation, each filter boat or product canister holds $22 \mathrm{~kg}$ of plutonium oxide in a volume $<2 \mathrm{~L}$, which, to a divertor, is a highly desirable material form.

These characteristics describe the nuclear material in the main process streams. There are numerous waste and scrap sidestreams that must also be safeguarded, but generally their plutonium concentrations are much lower.

\section{The Facility}

1. The Reprocessing Plant. The major areas of the reprocessing plant, spent-fuel receiving and storage, fuel processing, plutonium-nitrate storage, and the analytical laboratory, are shown in Fig. 5. The spent-fuel receiving and storage, fuel processing, and plutonium-nitrate storage areas are located in the separations facility, which is a several-story, massive concrete structure. The two-level analytical laboratory is located in a contiguous structure. Detailed information on the reprocessing facility may be found in Refs. 5 and 6.

Spent fuel is shipped to the facility in shipping casks, either by truck or by rail. Fuel bundles are removed from the casks and stored in canisters until they are required for processing. Normal handling and storage operations are performed underwater; transport is by overhead crane. When required for processing, bundles are transferred by underwater conveyor to the remote process cell.

The remote process cell contains the shearing and dissolving operations as well as the high-level liquid-waste concentrator. In this cell, fuel is sheared and dissolved; the undissolved hulls are removed from this cell to the remote maintenance and scrap cell. All operations in this cell are remote, including maintenance. Equipment may be removed to the crane and equipment maintenance gallery, located at one end of the cell, for maintenance. A movable shielding door separates the gallery from the remote process cell to allow contact maintenance of equipment.

The remote maintenance and scrap cell is located below the crane and equipment maintenance gallery. Hulls are transferred to this cell through an access port from the remote process cell. The hulls are transferred to a container, which is then placed in a cask at the cask-loading station, for removal from the cell. The cell is also used for 


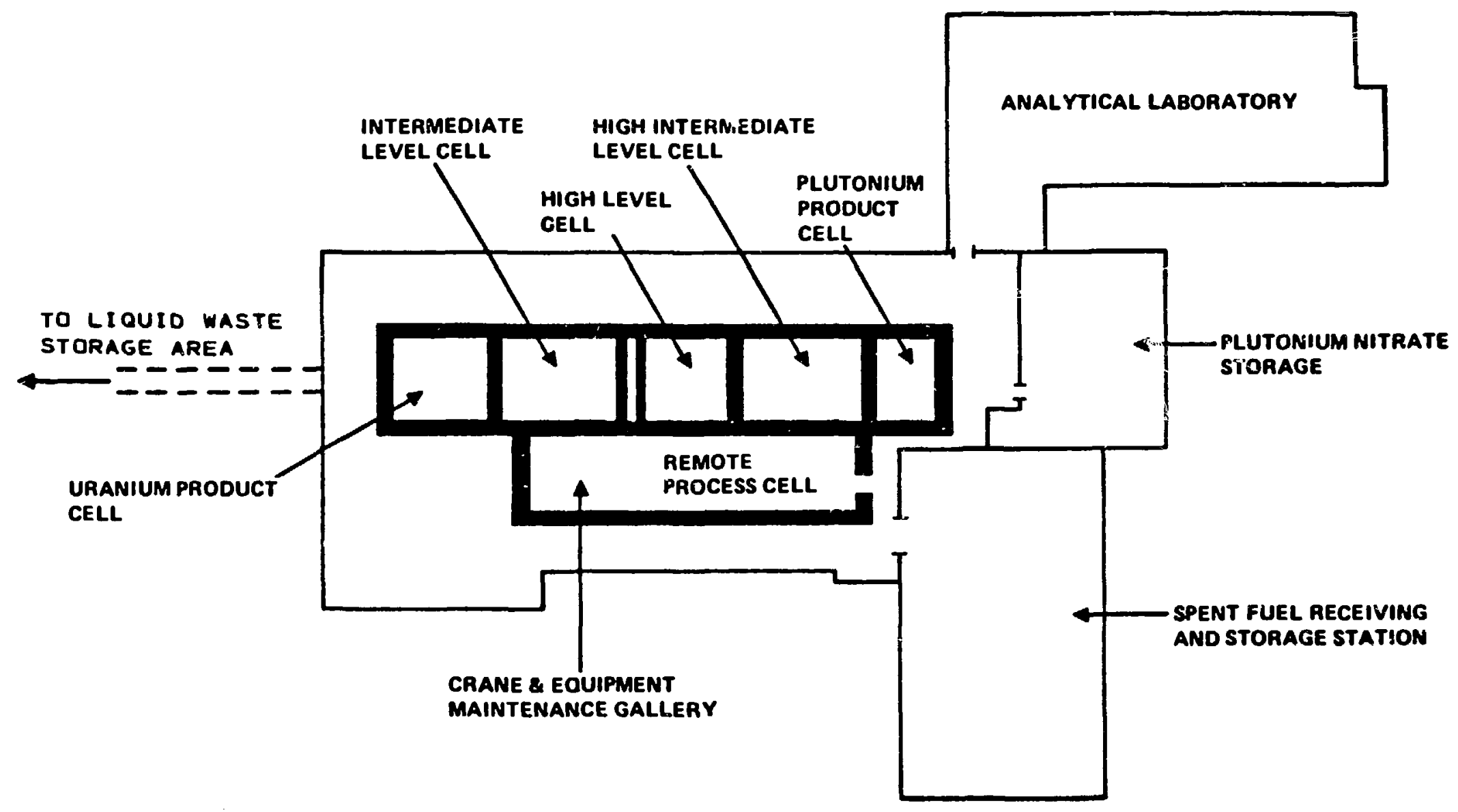

Fig. 5. Separations process building arrangement (conversion not shown). 
decontamination and maintenance of equipment. All operations in this cell, including maintenance, are performed remotely.

The high-level, intermediate-level, high-intermediate-level, uranium-prciduct, and plutonium-product cells sontain the equipment for the remainder of the processing described in Sec. Il.B.l. All nc:mal operations in these cells are performed ramotely; however, provisions are made for contact maintenance. Before a cell is entered for maintenance, all process material is removed and the cell is decontaminated.

The major streams from these cells are plutonium and uranium product streams and high-and intermediaie-level waste streams. Other penetrations to and from these cells include cooling water, air and steam lines, cold chemical feed, instrument lines, and sampling.

Plutonium nitrate is stored in slab tanks until transferred to the conversion facility. The plutonium nitrate is gravity fed from the plutonium-product cell, but is pumped between tanks or to the conversion facility. This is a contact maintenance area; however, maintenance is performed only after process materials are removed. Some operations in this area are performed in gloveboxes.

The analytical laboratory contains facilities for analysis of samples of process materials. Samples are taken from the separations and plutonium-nitrate storage facilities and transferred to the laboratory gloveboxes through pneumatic tubes. Laboratory operations are performed in gloveboyes, which include bag-out facilities for transfer of materials and waste.

2. The Conversion Plant. The base-line conversion facility is based on a DuPont design discussed in Refs. 7 and 8 . The plant consists of a reinforced concrete structure that houses the conversion process cells and the associated auxiliary equipment. $A$ reinforced concrete vault is provided for $\mathrm{PuO}_{2}$ storage.

All plutonium operation:; are remotely controlled and occur within closed, shielded cabinets. Glovebox access tos the process cabinets, following equipment cleanout and decontamination, is provided for maintenance.

To ensure continuous operation, a spare liquid process line, from feed receipt to precipitate filtering, is maintained in parallel with three active liquid-process lines. The iiquid processing is semicontinuous; solids handling, which includes filter-cake drying and calcining followed by product piackaging and assay, proceeds in a batch mode. A network of mechanical conveyors, which link the filtration stations to the product assay station through three parallel calcining ovens, provides remote handling of solids. The 
finished product is placed in sealed containers and is remotely transfurred to the vault. A single recycle process line and the cold chemical preparation facilities are also located within the plant.

\section{DIVERSION THREATS AND TYPES OF COUNTERMEASURES}

\section{A. Introduction}

The objective of international safeguards, as set forth by the IAEA ${ }^{4}$ is timely detection of diversion of significant quantities of nuclear material from peaceful nuclear activities and deterrence of such diversion by the risk of early detection. This report addresses the problem of covert diversion by a host nation operating an LWR spent-fuel reprocessing facility. With proper design, overt diversion should be detectable by the international safeguards system, particularly if the techniques for detecting covert diversion are effective.

Detecting covert national diversion in the international safeguards context is a significantly different problem from that of detecting, by means of a State's safeguards system, covert subnational diversion. The subnational diversion threat is constrained by lack of manpower and resources available to the divertor within the facility. Such constraints are much less severe in the case of national diversion. It is conservative to assume that the host nation can command whatever manpower and resources might be required to reach the diversion objective. Although surveillance measures and the presence of inspectors place de facto limits on certain illicit activities, a host nation that is attempting diversion might actively subvert the materials accounting and containment and surveillance measures that form the backbone of international safeguards, or at least ignore such subversive activities by others. This fact mandates an international safeguards system that compensates through various means, including self-protection techniques, for the potential malevolence of the host state.

Materials accounting and containment and surveillance are both important international safeguards measures. Materials accounting attempts to detect diversion by monitoring all normal process streams to determine that all material is accounted for at all times. In containment and surveillance, a containment is established around the normal process streams and surveillance measures are applied to detect any abnormal movement of material through the containment and to detect activities that might lead to such abnormal movement. Further: materials accounting confirms the effectiveness 
of containment and surveillance, and containment and surveillance protects the materials measurement and accounting system. Thus, these measures are complementary.

The key importance of materials accounting stems from its ability to quantify the diversion and its significance and from its ability to provide continuity of knowledge about the state of nuclear material, both in time and in location within the nuclear fuel cycle. By nature, however, materials measurements are imprecise. Containment and surveillance provides additional capability in that, by looking for any abnormal movement of material, it attempts to detect diversion that could be hidden in the inherent error structure of the materials measurement system. Furthermore, containment and surveillance provides an independent means for detecting diversion on a timely basis.

The subsequent section discusses some of the possible diversion schemes, and the last section outlines some of the types of countermeasures that should be effective. Section IV describes the technical approach for developing these countermeasures.

\section{B. Diversion Threats}

Covert diversion strategies fall into two categories. The first exploits the iriherent detection limits and statistical uncertainties of properly runctioning materials accounting and containment and surveillance systems to conceal a lower level of diversion. In the second category, the divertor deliberately degrades or modifies the safeguards system or the process to conceal a potentially larger diversion by data falsification, instrument tampering, or covert process-line changes. The first (passive) approach has fewer detectable characteristics, whereas the second (active) category is subject to detection by efficient inspection, containment and surveillance, and accounting techniques. The active strategies lack the advantages of the passive by usually being unambiguous when discovered and by also being violations of international agreements even if the diversion attempts themselves are not made.

\section{Diversion Hidden by Measurement Uncertainties. Balances drawn by the} materials accounting system are never closed exactly to zero because of measurement errors and statistical uncertainties. The usual practice is to estimate the standard deviation of the materials balance on the basis of historical information concerning the measuring instruments' characteristics. Each materials balance is considered to be abnormal only if it differs from zero by more than two or three standard deviations.

The diversion opportunity arises because of the size of the standard deviation of the materials balance. That is, if the alarm level is set at two standard deviations, diversion of an amount of ruclear material equal to two standard deviations would have a 
$50 \%$ chance of not being decected. Thus, in a reprocessing plant of the size of the base-line facility, a two-standard-deviation alarm level of $1 \%$ of throughput for a 6 -month period correspunds to $75 \mathrm{~kg}$ of plutonium. Note also that a 6 -month accounting period affords a divertor 6 months of diversion opportunity before being de:ected.

The divertor may chocse to take nuclear material in any of many fashious; the extreme cases are a large single diversion and many smaller ones (skimming). If the materials balance period is of significant duration, for example, greater than a week, a goad diversion strategy would be to divert (abruptly) early in the period to prolong the time before possible detection. If the materials balance period is relatively short, skimming will tend to extend the detection time. However, the probability of detection by the containment and surveillance system increases with the number of diversion attempts if the divertor is using a pathway that is protected by the containment and surveillance system.

The divertor may decide always to divert material from one location in the process, or he may select any of several diversion points in the process. Generally, material taken from the proress after uranium-plutonium partitioning is most desirable because of its relatively high concentracion and freedom from fission products. Materials accounting strategies must balance the diversion-related characteristics in various parts of the process against the actual and potential capabilities of materials measurements. For example, the creation of a materials balance area (or perhaps several) for the postpartition process, thus using the relatively good materials measurements in this area to the greatest advantage, minimizes the probability of successful diversion and circumscribes the choices of diversion location and pattern.

2. Diversion Unobserved by Containment and Surveillance. The containment and surveillance system has two main parts:

- the containment, which comprises the physical bourndaries within which nuclear material is expected to remain; and

- surveillance, which is composed of human and/or instrumental observations that can detect movement of material through the containment barrier or can detect activities that may lead to violation of the containment.

Surveillance of the complete facility reduces the probability of successful diversion from the prepartition part of the process in the absence of covert process changes (see below). Such material is highly contaminated with fission products, and the plutonium concentration is low; furthermore, nuclear material resides in the storage pool as 
spent-fuel assemblies. Thus, diversion activities in this area would have to be concealed as normal activities because diversion would require massive shielding, bulky equipment, and several persons, all of which should be highly visible as abnormal.

Surveillance of the process line differs in post-partition processing because a significant quantity of nuclear material could be more easily removed in small quantities. Dutection efforts in this area must concentrate on using the most sensitive instruments possible and on careful placement of those instruments. For example, portal monitors at the access points to the operating galleries might be effective against many strategies.

3. Instrument Tampering. One obvious diversion technique would be to render some key safeguards instrument inoperative; however, if all safeguards instrumentation is designed, as it should be, to be tamper-indicating and self-checking, then tampering would, at the least, result in an investigation by the international safeguards authority. The same is true of inducing an instrument bias, by deliberate miscalibration for example. Continued disruptions of this nature, such as might be required for long-term diversion, would be cause for additional suspicion and possible action.

Even if the tamper-indicating features were missing or had been defeated, the divertor still would have to face the problem of just what to do with the instrument. In generol, to maintain the appearance of compliance, he must do the tampering twice: once to subvert the instrument and once to restore it to normal operation. For materials accounting instrumentation, the period of subverted instrument operation must roughly correspond to the period during which diversion occurs. Otherwise, the divertor runs the risk of being discovered by virtue of an apparent instrument malfunction. Furthermore, if he tampers with an instrument that measures in-process inventory, a maturials balance period that includes and is longer than the period of subverted instrument operation will yield materials accounting data that are unaffected by his attempted deception. Therefore, he must tamper with two instruments, including a transfer-measuring instrument as well, in a coordinated fashion, which would then affect the materials balances in the adjacent areas of the process. Thus, it would be extremely difficult, using this kind of instrument tampering, to divert very much more than by using the techrique of diversion hidden by measurement uncertainties. In addition, the divertor must still defeat the containment and surveillance system, and he also faces the prospect of detection through independent measurement verification by the inspector. 
A more subtle scheme would be to increase the uncertainty in some measurement(s), perhaps by artificially increasing the electronic noise in an instrument. This step would actuaily take place at the time of instrument maintenance and recalibration. Again, the diversion opportunity would not be greatly increased, and a carefully monitored measuremerits control program would make this step difficult. Furthermore, there are nonparametric statistical techniques $5,7,9,10$ that do not depend upon knowledge of the measurement uncertainties for efficient diversion detection. There are also other statistical techniques ${ }^{11}$ that search for abnormal changes in measurement uncertainties.

4. Data Falsification. This diversion scheme is very similar to instrument tampering, except that it occurs at the software level in the data base instead of at the hardware level in the instrument. Similar comments to those concerning instrument tampering apply. Concealment of diversion significantly larger than that which can be hidden by measurement uncertainties requires data falsification for extended periods of time and for several areas of the process, perhaps extending to more than one facility. The possibility of making a mistake in such a complicated diversion scheme increases the risk of detection.

5. Covert Process Changes. One example of this diversion path is the "sneak circuit," an uncharted pipe, built into the facility during construction or clandestinely added later, for surreptitiously withdrawing nuclear material from the process line. This technique could defeat the containment and surveillance and process-monitoring functions, but it can still do no better than diversion hidden by measurement uncertainties because the materials accounting capability is unaffected.

Another variation of the sneak circuit consists of two pipes, one for clandestine feed and another for clandestine product. This scheme would allow the divertor to use the facility, or parts of it, to process material that he had skimmed and stashed away or obtained elsewhere. The only indication of such a situation would be an increase in in-process inventory, which would go unnoticed by the materials accounting system unless a balance were drawn whise the surreptitious processing was going on. Monitoring of process-control variables should be highly effective against this type of diversion. The best defense against either of these scenarios is adequate monitoring and inspection procedures during and after construction or maintenance activities because these scenarios clearly weaken the normal safeguards system. 
A third possibility is deliberate misoperation of the process to create upset conditions that make materials accounting measurements more difficult and uncertain. For example, the divertor might introduce unusually large amounts of fission products into the plutonium purification process. Such an event would decrease the effuctiveness of near-real-time materials accounting measurements until the fission products were eliminated.

A final, more obvious scheme would be to process nuclear material while the safeguards system was inoperative. As an example, the host nation might announce that the facility is going to be shut down for maintenance or because there is no material to be reprocessed at present. If the safeguards system were also shut down, the host nation could do as it pleased.

These last two diversion schernes could be counteracted by safeguards procedures agreed upon before facility startup. For example, if process upsets occur that affect safeguards, then provision must be made to allow the safeguards system to "catch up." Such diversion scenarios, while patently transparent, emphasize the fact that safeguards is a full-time endeavor, from facility design to facility decommissionir.

\section{Some Types of Countermeasures}

Safeguards improvements to combat these diversion threats are generally of three kinds: (1) technical safeguards measures, (2) process modifications, and (3) institutional arrangements.

1. Technical Safequards Measures. An effective international safeguards system requires the use of both materials accounting and containment and surveillance to provide detection of diversion from any point in a facility. Improved safeguards depends on a coherent, balanced application of the techniques to the complete facility and to the entire fuel cycle.

A significant improvement results from using dynamic materials accounting, $5, i, i 2,13$ which is based on recently developed NDA technology, conventional measurement methods, and sophisticated data-analysis techiques supported by computer and data-base management technology. The fundamental idea is to draw dynamic materials balances in near-real time about relatively small portions of the process, called unit-process accounting areas. This approach increases the timeliness and sensitivity of materials accounting because balances can be drawn more frequently about smaller amounts of material. 
For the base-line facility, each of the process areas discussed in Sec. II and shown in Figs. 2-4 could be considered as a unit-process accounting area, although spent-fuel receiving and storage might be an item-control area if satisfactory spent-fuel verification measurements are unavailable. In the postpartition part of the process, balances can be drawn almost as often as desired, perhaps every one or two hours. In the prepartition area, the lack of appropriate measurement techniques may dictate that balances be drawn less often; however, as discussed earlier, this may be entirely suitable because of the nature of the nuclear material and the effectiveness of containment and surveillance measures in this area.

It must be emphasized that dynamic materials accounting supplements, but does not replace, present shutdown, cleanout, physical-inventory procedures. Physical inventories are still necessary to provide materials accounting fiducials and a periodic zero-base inventory, although the physical inventories may not need to be takeri as frequently.

If dynamic materials accountinit is implemented by the host nation as the State's accounting system, then the international inspectorate must be able to verify the results independently. This function could be performed as currently proposed for a conventional State's accounting system, that is, independent measurements linked to the pnysical inventory structure. In this case, the verification procedures are no different than for a conventional accounting system. However, dynamic materials accounting offers the possibility of more extensive verification activities, particularly if resident inspectors are allowed and are equipped with suitable instrumentation, because there are more measurement opportunities, both in time and in location. Furthermore, the much more comprehensive data from the dynamic materials accounting system facilitate checks of internal consistency of the State's accounting data between physical inventories.

Containment and surveillance has two functions. One is to detect diversion of SNM, and the other is to detect tampering with safeguards instrumentation. Containment and surveillance attempts to provide independent detection of diversion in those areas of the process where materials accounting is most effective, such as the postpartition area. In addition, containment and surveillance provides the primary means of diversion detection in areas where materials accounting is less effective and ensures the integrity of the materials accounting data acquisition system.

Two major types of containment are fixed and mobile. An example of fixed containment is the wall surrounding a process cell, and an example of a mobile containment is a plutosium-oxide product canister. Surveillance of a fixed containment 
requires instruments such as portal and piping monitors that can deltect movement of material through existing cuntainment penetrations and instruments such as structural disturbance sensors and cameras that can detect activities associated with creation of new penetrations. Mobile containments must be accounted for on an item basis and have some form of identifier, such as a seal, as well as some form of monitoring to ensure that any violation of the integrity of the container is detected.

Containment and surveillance methods may be combined to provide more effective detection. For example, stored spent fuel might have seals as identifiers, whereas acoustic instruments would be used to detect disassembly operations. Further, radiation monitors could be used to detect unusual movement of fuel assemblies, and structural disturbance sensors and cameras would monitor the building walls.

The possibility of instrument tampering requires that all international safeguards instrumentation be hardened and tamper-indicating. To some extent, this requirement can be satisfied by the expanded verification activities discussed above; it also means that international involvement in the measurement control and maintenance programs is necessary.

The containment and surveillance system can also assist, through direct observation of the instrument environment, in detecting instrument tampering. The task is easier if most instruments are automated and interfaced directly to the materials accounting computer system; in that case, the State has no reason to interact with the instrument, except for the maintenance and calibration, in which the international inspectorate would also participate.

The additional surveillance technique of monitoring process variables for unauthorized or nonstandard materials movements probably complements materials accounting best in those areas where materials balance uncertainties are larger than desirable. Therefore, the prepartition area would be a likely location for extensive process-monitoring efforts.

The problem of data falsification can be addressed in several ways, the most obvious being to transmit safeguards data simultaneously to the State's accounting system and to the international authority. The data might be received at a remote location (say Vienna) via satellite link, at a nearby off-site location by land line or microwave, or at a location within the facility. One possible method is a combination of these: sending the data to an on-site location for immediate use and to an off-site data-collection center for backup and archival storage. In all cases, the transmission mode must be tamper-indicating. The on-site receiver of the data could be the same computer used by the State's accounting system, but security and computational priority 
problems would probably dictate that the international inspectorate have its own on-site computer to receive and process the data without interference from the State. It could compare its results with the off-site analyses, and it could verify the integrity of the State's data base.

2. Process Modification for Safequards Improvement. Many process-related changes for improving the safeguardability of the base-line process have been suggested in Refs. 5 and 7. Most are aimed at decreasing materials accounting uncertainties. For example, operating the process in a batch mode is usually beneficial because balances can be drawn about individual batches of nuclear material. Another modification is the use of centrifugal contactors instead of pulsed columns or mixer-settlers; centrifugal contactors are desirable because they have very small in-process inventories, and therefore less measurement uncertainty. A third modification is the use of several smaller, parallel process lines to achieve the desired plant capacity. This would allow smaller unit-process accounting areas, again decreasing measurement uncertainties.

Some of these changes would be costly in terms of money and operational impact on the process; some may be impracticable in a production environment. However, beneficial and benevolent process changes are possible if safeguards considerations are incorporated sufficently early in the design phase of such facilities.

3. Institutional Arrangements. Institutional arrangements are concerned with fixing the responsibilities for the operation and management of the facility and the safeguards system and their. interactions. For example, it is becoming widely recognized that continuous inspector presence forms an important part of international safeguards and one that should be included in most new agreements. Similarly, the "Bonded Crucial Facility" (BCF) concept ${ }^{1,2,7}$ is another kind of institutional arrangement directed at identifying and treating potential weaknesses that could be profitably addressed by enhanced, specialized safeguards techniques.

Another such concept is the multinational reprocessing center, for which several new safeguards possibilities arise. Weinstock ${ }^{14}$ has this to say:

"So far, in discussions of multinational facilities, it is assumed that the IAEA role would be the same as it is now: i.e., it would be limited to independent verification of the veracity and effectiveness of a safeguards system operated by the facility. But the multinational character 


\begin{abstract}
opens up another possibility, namely that the IAEA itself have primary responsibility for carrying out safeguards operations (except for physical protection). Multinational operation of the facility makes this more acceptable than in the past because one of the main traditional reasons for limiting inspector access, namely the possible compromising of commercial or national security secrets, would be less compelling under these circumstances. The principle of national sovereignty, which also limits the role of the IAEA, would likewise be diluted by multinational operation."
\end{abstract}

He goes on to point out that it may be appropriate for the IAEA and the operator to exchange safeguards roles, that is, to let the operator verify the IAEA's results. Furthermore, this arrangement would cast the international safeguards system in the role of providing an essential service to the operator.

\title{
IV. TECHNICAL APPROACH
}

\section{A. Objectives}

The primary purpose of the overall study is to provide design concepts for safeguarding an LWR reprocessing/conversion facility in the international environment. This purpose will be pursued from the point of view of international safeguards and will, therefore, depend heavily on the complementary ideas of materials accounting and containment and surveillance. Therefore, an important part of the effort will be to develop techniques for designing an international safeguards system that integrates the applicable technologies.

Effective integration first requires detailed uriderstanding of the characteristics and capabilities of both materials accounting and containment and surveillance. Only after this step, which is the first to be undertaken in the study, can possible tradeoffs and overlaps begin to be examined. The secondary purpose of the effort is to learn how to design such integrated systems and to provide the methodology to other safeguards systems designers. 
Besides the integration methodology, the study will result in a set of safeguards options for an international LWR reprocessing/conversion facility. The options will cover ranges of effectiveness and cost, and will include several implementation alternatives.

\section{B. Study Procedure}

The first three steps in the study will be performed separately by LASL and Sandia. LASL will concentrate on materials accounting, and Sandia will investigate the containment and surveillance problem. As shown in Fig. 1 , the results of these efforts will be available at about the mid-point of the study. At all stages, work will be coordinated closely to ensure effective integration of systems design and evaluation. The following are major steps to be taken.

1. Define Diversion Strateqies. Definition of a diversion strategy includes specifying (1) the lucation in the process from which SNM is to be diverted, (2) the total amount of SNM to be diverted, (3) the time evolution of the diversion (for example, uniform, random, single diversion), (4) any required ancillary, subversive activities, such as instrument tampering or clandestine process modifications, and (5) the diversion path, or method of removing SNM from the facility. Clearly, these specifications are not entirel' inclependent; for example, specifying (1), the location of diversion, fixes the initial point of (5), the diversion path. Furthermore, some specifications are more important for materials accounting than for containment and surveillance, and vice-versa. Thus, materials accounting is primarily concerned with the first three items, somewhat less with item 4, and even less with item 5 . Containment and surveillance are involved in all five items, but 4 and 5 tend to dominate. Of course, there are exceptions to these observations depending on the particular diversion strategy. For example, records falsification under item 4 is of particular importance to materials accounting.

Logic trees that describe the events associated with diversion offer a powerful and convenient means of identifying and presenting diversion strategies. Sandia has used this technique to good effect for some time in their work on physical protection and containment and surveillance systems. $15-19$

The top event of the logic tree is diversion of SNM from the facility. The tree is then developed according to the five strategy specifications given above. Intermediate events show general operations that may apply to more than one diversion path. Basic events describe particular operations that, potentially, could be detected by the 
safeguards system. An example of a simple logic tree for diversion is shown in Figs, 6-8. Figure 6 explains the symbols used in the tree, Fig. 7 shows the top of the tree, and Fig. 8 expands one of the subtrees to complete the logic tree.

The cut sets of the logic tree indicate potential diversion strategies. In the example tree, the four cut sets, or diversion strategies, are:

- events $A 1-1$ and $A 2$,

- events $A 1-2$ and $A 2$,

- events $B 1$ and $B 2$, or

- diversion from area $C$.

Diversion may occur from any combination of areas $A, B$, and $C$. If diversion from area $A$ is to occur, both events $A 1-1$ and $A 2$, or events $A 1-2$ and $A 2$ must occur.

In practical application, the generic events listed on the logic trees of Figs. 7 and 8 would be replaced by descriptions of particular events in the diversion strategies. It will be apparent from the logic tree that some diversion strategies are much less likely either to be attempted or to be successful, and some preliminary screening of such strategies may be possible. However, care must be taken not to discard significant strategies at this point.

2. Design Materials Accounting and Containment and Surveillance Systems. At this stage, materials accounting and containment and surveillance systems are designed separately by LASL and Sandia, respectively, to address the diversion strategies identified by the jointly developed logic tree. The result of each effort will be a set of systems designs having ranges of complexity and capability.

The materials accounting system will be based on the concepts discussed in Sec. III.C.1. and described in detail in Refs. 5 and 7, with appropriate modification for the international safeguards context. The logic tree will help to identify important parts of the materials accounting system, some of which would not be obvious without a thorough, careful analysis.

Design of the containment and surveillance system will make extensive use of the logic tree in the following way. A list of candidate sensors must be developed (see Refs. 15-19) that may be used to detect the events identified in the cut sets of the logic trees. These sensors should be applied to more than one event in each of the cut sets to protect against single-point failures. Covering of all possible strategies can be ensured by obtaining the cut sets of the complement logic tree. The complement tree has all the branches that the original tree has, but the AND and OR gates are interchanged, and the 
BOX: An event whose causes are developed through logical connections, to other events

CIRCLE: Basic event

DIAMOND: Intermediate event that

will not be further developed

OR GATE: The occurrence of any input(s) can resuli in an output

AND GATE: All inputs must occur to resuit in an output

TRANSFER: Connects different parts of the fault tree together

Fig. 6. Logic tree symbols. 


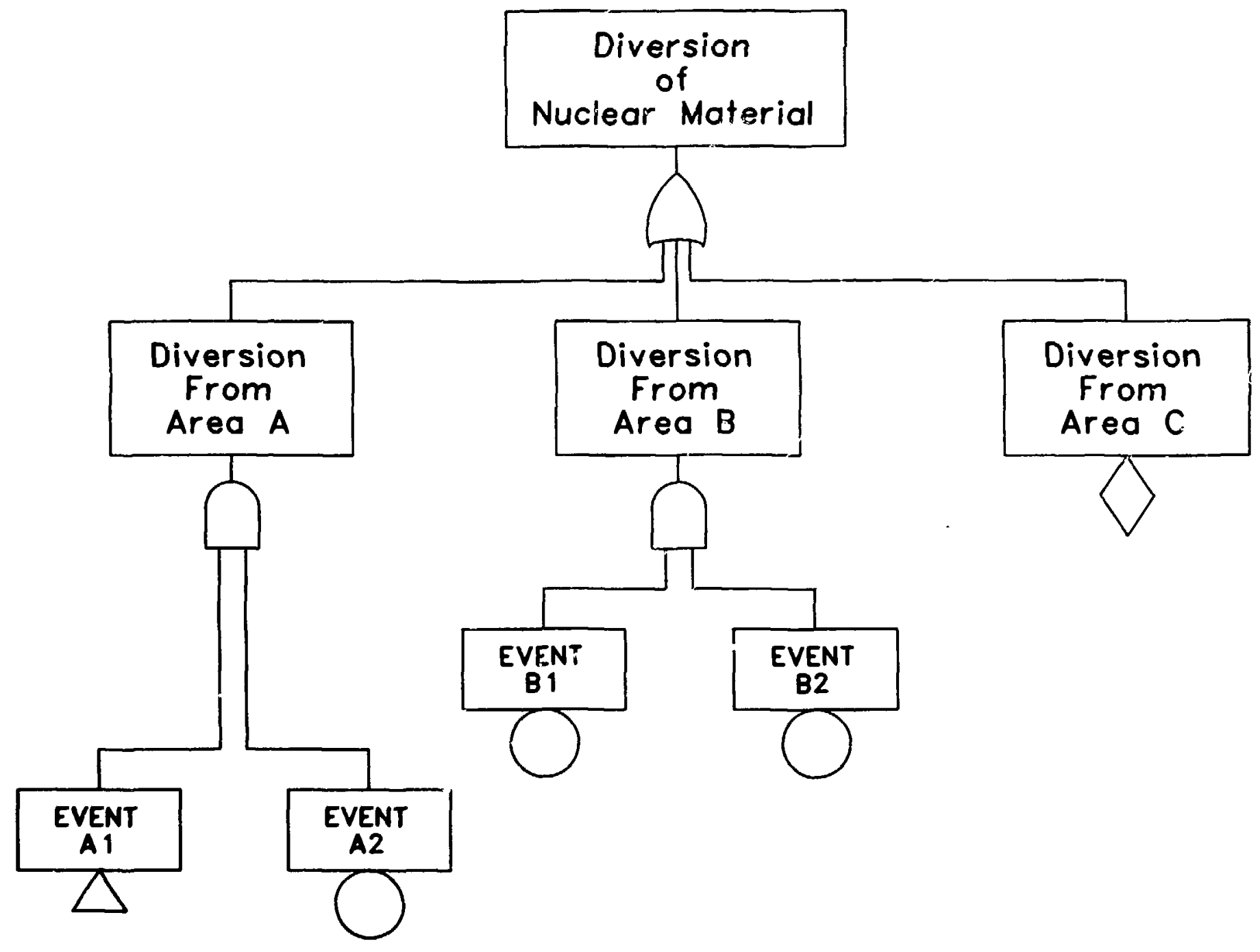

Fig. 7. Typical logic tree with incomplete subtree under event Al. 
events in the complement tree are "detection of" the events in the original tree. For example, the top event would be "detection of diversion." The cut sets of the complement tree are sets of detection events that will cause the top event to occur. All of the detection events in one of the complement cut sets must be achievable if diversion by each strategy is to be detected. For the example tree, the four complement cut sets are:

- $\operatorname{detect} A 1-1, A 1-2, B 1$, and diversion from area $C$,

- $\operatorname{detect} A 1-1, A 1-2, B 2$, and diversion from area $C$,

- $\operatorname{detect} A 2, B 1$, and diversion from area $C$, or

- $\operatorname{detect} A 2, B 2$, and diversion from area $C$.

The complement tree provides guidance on the locations and types of instruments necessary for an effective containment and surveillance system.

3. Evaluate Diversion-Event Characteristics. On the basis of the systems designs obtained in Step 2 and of the complement logic tree, and using standard Monte Carlo modeling and simulation techniques, ${ }^{5,7}$ each diversion stracegy can be characterized according to its attributes as related to materials accounting and containment and surveillance. This will be done for each systems option and for both materials accounting and containment and surveillance separately.

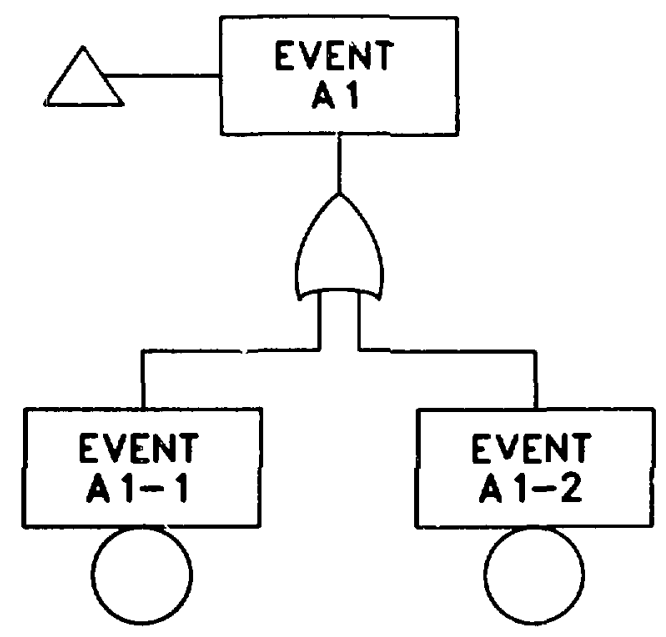

Fig. 8. Completion of subtree under event Al.
At this point, LASL will document the materials accounting results of the first three steps, and Sandia will report on containment and surveillance results. These two reports will form the technical basis for the follow-on systems integration effort and the final integrated report.

\section{Evaluate Overall Diversion-} Event Characteristics. This is the first step toward systems integration, and it consists of combining the two sets of characteristics, one set for materials accounting and orie set for containment and surveillance, into one overall set of 
characteristics for each diversion strategy and for each systems implementation option. One of the methudological problems to be solved concerns the combination; the basic difficulty is that the features of materials accounting and containment and surveillance are generally quantified in incommensurate terms.

The second part of Step 4 is to identify those diversion strategies that have the most undesirable attributes, for example, greatest probability of success, or longest detection time; that is, find the critical diversion paths. The definition of "critical diversion path" is unknown at this time and will have to be determined as part of the methodology development.

Identification of the critical diversion paths then provides guidance for modifications of the integrated systems options; perhaps too much emphasis is placed on one diversion strategy and materials accounting or containment and surveillarce requirements could be relaxed, for example. Or it could be that some diversion strategy is not adequately covered, and a systems upgrade or restructuring might be necessary. If modification is necessary, then a partial rework of Steps 2, 3, and 4 will be required.

5. Assess Costs of the Options. In terms of systems capital costs, this step is straightforward. However, part of the hidden cost of any safeguards system is its impact on process operations, which is somewhat more difficult to address quantitatively. Such costs will be considered to the extent possible.

6. Issue Joint Report. This is the final step of the study and will document the results and the methodology. It will be aimed at assisting other safeguards systems designers and at assessing the capabilities of current technology or reasonable extrapolations thereof. The report will evaluate a number of potential safeguards systems options on the basis of effectiveness, cost, operational impact, and technical feasibility. In addition, the report will identify future technology development requirements.

\section{ACKNOWLEDGMENTS}

The authors gratefully acknowledge the support and guidance of Sharon Klein, Margaret Scott, and Nock Soun Han of Los Alamos Scientific Laboratory and of Drs. T. A. Sellers, W. C. Myre, and J. M. DeMontmollin of Sandia Laboratories, Albuquerque. 


\section{REFERENCES}

1. R. J. Dietz in "Nonproliferation Strategies: Foreign Spent-Fuel Reprocessing Plants," draft discussion paper (100 pp) (June 1977).

2. R. J. Dietz, E. A. Hakkila, and J. P. Shipley, "Preliminary Evaluation of the Tokai Engineered Safeguards System (TESS)," private communication to ERDA-DSS (14 pp) (July 1977).

3. "Treaty on the Non-Proliferation of Nuclear Weapons," IAEA INFCIRC/140 (April 1970).

4. "The Structure and Content of Agreements Between the Agency and States Required in Eonnection with the Treaty on the Non-Proliferation of Nuclear Weapons," IAEA INFCIRC/153 (June 1972).

5. E. A. Hakkila, D. D. Cobb, H. A. Dayem, R. J. Dietz, E. A. Kern, E. P. Schelonka, J. P. Shipley, D. B. Smith, R. H. Augustson, and J. W. Barnes, "Coordinated Safeguards for Materials Management in a Fuel Reprocessing Plant," Los Alamos Scientific Labortory report LA-6881 (September 1977).

6. "Barnwell Nuclear Fuel: Plant Separations Facility--Final Safety Analysis Report," Docket 50-332, Allied-General Nuclear Services, October 10, 1973.

7. H. A. Dayem, D. D. Cobb, R. J. Dietz, E. A. Hakkila, E. A. Kern, J. P. Shipley, D. B. Smith, and D. F. Bowersox, "Coordinated Safeguards for Material Management in a Nitrate-to-Oxide Conversion Facility," Los Alamos Scientific Laboratory report L.A-7011 (April 1978).

8. "Composite Quarterly Report: Light Water Reactor Fuel Cycle," Savannah River Laboratory report DPST-LWR-77-2-1 (July 1977).

9. James P. Shipley, "Decision Analysis for Nuclear Safeguards," Am. Chem. Soc. 1978 Spring Meeting on Nondestructive and Analytical Chemical Techniques for Nuclear Safequards, Anaheim, California, March 12-17, 1978.

10. J. P. Shipley, "Decision Analysis for Dynamic Accounting of Nuclear Material," Am. Nucl. Soc. Topical Meeting, Williamsburg, Virginia, May 15-17, 1978.

11. J. P. Shipley, "Efficient Analysis of Dynamic Materials Accounting Data," Proc. 19th Annual Meeting of Inst. Nucl. Mater. Manag., June 27-29, 1978.

12. G. R. Keepin and W. J. Maraman, "Nondestructive Assay Technology and In-Plant Dynamic Materials Control--DYMAC," in Safequarding Nuclear Materials, Proc. Symp., Vienna (1976), Paper IAEA-SM-201/32, Vol. 1, pp. 304-320.

13. R. H. Augustson, "Development of In-Plant Real-Time Materials Control: The DYMAC Program," Proc. 17 th Annual Meeting Inst. of Nucl. Mater. Manag., June 22-24, 1976. 
14. E. V. Weinstock, "Some Ideas on Multinational Facilities," Brookhaven National Laboratory Memorandum (April 28, 1978).

15. J. P. Holmes, "Conceptual Design of a System for Detecting National Diversion of LWR Spent Fuel," Sandia Laboratories report SAND78-0192 (October 1978).

16. J. L. Todd, "Containment and Surveillance for International Safeguards," Sandia Laboratory internal cocument (March 20, 1978).

17. C. S. Sonnier and M. N. Cravens, "Preliminary Concepts for Detecting National Diversion of LLWR Spent Fuel," Sandia Laboratories report SAND77-1954 (April 1978).

18. J. M. McKenzie, J. P. Holmes, L. K. Gillman, and J. A. Schmitz, "Surveillance Instrumentation for Spent Fuel Safeguards," Sandia Laboratories report SAND78-1262 (August 1978).

19. T. A. Sellers, "Preliminery Concepts for Detecting National Diversion of LWR Spent Fuel," Sandia Laboratories report SAND78-1628C (September 1978). 